\title{
Methods for Measuring Diffusion of a Social Media-Based Health Intervention
}

\author{
Sean D. Young1*, Thomas R. Belin², Jeffrey D. Klausner3 ${ }^{3}$, Thomas W. Valente ${ }^{4}$ \\ ${ }^{1}$ UCLA Center for Digital Behavior, Los Angeles, USA \\ ${ }^{2}$ Department of Biostatistics, University of California, Los Angeles, Los Angeles, USA \\ ${ }^{3}$ Department of Medicine, University of California, Los Angeles, Los Angeles, USA \\ ${ }^{4}$ Department of Preventive Medicine, USC Keck School of Medicine, Los Angeles, USA \\ Email: sdyoung@mednet.ucla.edu
}

Received 17 March 2015; accepted 18 April 2015; published 29 April 2015

Copyright (C) 2015 by authors and Scientific Research Publishing Inc.

This work is licensed under the Creative Commons Attribution International License (CC BY).

http://creativecommons.org/licenses/by/4.0/

(c) (i) Open Access

\begin{abstract}
This study evaluated the feasibility of measuring diffusion from a social networking communitylevel intervention. One year after completion of a randomized controlled HIV prevention trial on Facebook, 112 minority men who have sex with men (MSM) were asked to refer African-American and/or Latino sex partners to complete a survey. Results suggest that, compared to non-referrers, referrers spent more time online, controlling for age, race, education, and condition. Over $60 \%$ of referrals reported hearing about the intervention, and over half reported that the referrer talked to them about changing health behaviors. Results provide support and initial feasibility of using social networking for diffusing community-based HIV interventions.
\end{abstract}

\section{Keywords}

HIV Prevention, Social Networking Technologies, Diffusion of Innovations

\section{Introduction}

Diffusion of innovation interventions have been successfully used to promote health behavior change [1]-[3]. These interventions send socially-connected peer leaders into communities to increase health communication and endorse health-related social norms [4]. Peer leader interventions have focused particularly on HIV-affected groups (e.g., men who have sex with men (MSM)) both because of the significance of the HIV epidemic and direct role that social networks and sexual partners play in risk behaviors [5]. HIV peer leader interventions have been effective at reducing sexual risk behaviors, with sustained behavior change up to 3 years later [1] [6].

${ }^{*}$ Corresponding author. 
Prevalent use of social networking technologies allows researchers to use these platforms to deliver peer health interventions among online communities and to evaluate an intervention's success in spreading throughout participants' social networks to people outside of the initial intervention group [7]-[11]. For example, the Harnessing Online Prevention Education (HOPE) study was a randomized controlled peer-led HIV prevention intervention among African American and Latino MSM Facebook communities [8]. African American and Latino MSM peer leaders were randomly assigned to participants in Facebook communities to communicate either HIV prevention (intervention) or general health (control group) information. Results suggest that the intervention was effective in engaging community participants and creating effective HIV behavior change [12] [13]. However, it is unknown whether participants discussed health-related information to other non-study participants in their social networks.

In fact, research on social networks and health has focused on diffusion that begins from one or more individuals, but has not evaluated whether and how information diffuses from groups, or online communities. For example, typically, researchers provide information to individual "seed" participants and measure how information spreads from these individuals to others [10]. Social networking technologies, however, allow researchers to intervene at the community level with the possibility that group participants would spread information to others who are outside of the online group, providing a potential model for rapid and widespread delivery of information. No known studies have explored this topic.

This study evaluates the feasibility of measuring diffusion from an online social networking community-level intervention. Specifically, we seek to determine 1) response rates of participants from a randomized controlled trial who were asked to invite their friends to complete a survey, 2) characteristics/predictors of participants who referred others, and 3) initial data on the feasibility of measuring diffusion from an online community-level intervention.

\section{Methods}

One year after completion of the HOPE online intervention, we emailed MSM participants who completed a baseline questionnaire $(\mathrm{N}=112)$. Participants were asked to contact $1^{\text {st }}$-degree (directly-linked) Facebook connections who were 18 years of age or older, living in Los Angeles, and African American and/or Latino sex partners, and ask them to email us if they would complete a 45-minute survey. We use the term "seeds" to describe HOPE participants, and "referrals" to describe friends who emailed us requesting study information. Due to requirements from the institutional review board that the referral would contact the study investigators if he was interested (rather than the investigators being able to reach out to potential referrals), we do not know how many (unsuccessful) attempts were made by HOPE participants to recruit referrals as we only collected data if the referral emailed us requesting information.

Interested referrals were screened for eligibility online, including providing access to their Facebook network to improve data quality by ensuring that they were valid, non-duplicate Facebook users who were directly connected to a HOPE participant. Referrals were sent a link to a website with a 90-item questionnaire on Internet/ social media use, whether seeds had discussed the intervention and health behaviors with them, and their HIV/ sexual and drug use behaviors. For example, Internet and social media use questions asked, "How many hours a week do you spend online?” HIV history-related items asked whether they had ever been tested for HIV and had they received their results. Referrals who completed the survey received a $\$ 30$ gift card to an online store and the HOPE seed received a \$10 card.

\section{Analysis}

Descriptive statistics presented details on 1) seeds, broken down by whether they provided referrals, and 2) referrals, broken down by those referred from intervention versus control group participants. Chi-square tests assessed demographic differences in categorical variables among HOPE participants, Fisher's exact test confirmed analyses due to small sample size, and t-tests assessed differences in age. Logistic regression was used among HOPE participants to assess the relationship between providing a referral and amount of time spent online, controlling for age, race, education, and intervention condition.

\section{Results}

We received a total of 67 referrals, from 15 of the 112 (13.4\%) HOPE participants. Forty-four of the interested 
referrals (65.7\%) consented and completed the survey. Table 1 describes characteristics of HOPE seeds. We found initial differences in amount of time spent online among seeds who provided referrals and those who did not (Chi square, $\mathrm{p}<0.05$; Fisher's exact test, $\mathrm{p}=0.07$ ). In general, intervention participants and Latino participants appeared more likely to have provided referrals. Results from a logistic regression suggest that seeds who provided referrals spent more time online, controlling for age, race, education, and condition (Coeff $=1.71$, Confidence interval: $1.02-2.86, \mathrm{p}<0.05)$.

Table 2 provides data on referrals' demographic information, Internet use, and whether seeds discussed the intervention and changing health behaviors with them. Over $45 \%$ of referrals reported being Latino, over 50\% spent more than 3 hours online a day, and 68\% reported being Gay. Over 60\% of referrals reported hearing about the HOPE study, and over half of referrals reported that their seed talked to them about health behaviors. On average, referrals reported being slightly more likely to change their health behaviors as a result of talking to the referral.

\section{Discussion}

Social networking technologies are a feasible platform for delivering community health interventions and diffusing them throughout participants' social networks. Results suggest that 1) one year after a community-based intervention, a modest number of participants' social network connections contacted us asking to complete surveys to measure diffusion, 2) seeds who spend more time online are more likely to have led to referrals, and 3) health information from the intervention appears to diffuse through participants online networks to new individuals who did not receive the original intervention.

Results suggest that researchers attempting to study diffusion from a community-based intervention should recruit participants who are frequently online to increase likelihood of gaining referrals. One hypothesis for this result could be that people who are online more frequently would have more online connections and the potential to reach a larger number of people online. Although social network researchers typically hand-pick initial "seeds" and individually deliver an intervention to seeds to diffuse an intervention, the present results suggest an alternative method whereby researchers can recruit seeds who spend time online and have large online social

Table 1. Characteristics of seed MSM from an online social networking HIV prevention intervention, Los Angeles, CA 2011-12.

\begin{tabular}{|c|c|c|c|}
\hline & $\begin{array}{l}\text { Referrer/Seed Participant } \\
\qquad(\mathrm{n}=15)\end{array}$ & $\begin{array}{c}\text { Non-referrer Participant } \\
\quad(\mathrm{n}=97)\end{array}$ & Test Statistic \\
\hline Age (mean (SE)) & $34.53(3.43)$ & $31.73(.97)$ & -0.99 \\
\hline \multicolumn{4}{|l|}{ Race } \\
\hline African American & $2(13.3 \%)$ & 29 (29.9\%) & \\
\hline Latino & $12(80.0 \%)$ & $55(56.7 \%)$ & \\
\hline Other & $1(6.7 \%)$ & $13(13.4 \%)$ & 2.94 \\
\hline \multicolumn{4}{|l|}{ Education } \\
\hline High school or less & $8(53.3 \%)$ & 30 (30.9\%) & \\
\hline GED or Associate's degree & $2(13.3 \%)$ & $29(30.0)$ & \\
\hline Bachelor's degree & $4(26.7 \%)$ & $26(26.8 \%)$ & \\
\hline Graduate school & $1(6.7 \%)$ & $12(12.3 \%)$ & 4.3 \\
\hline \multicolumn{4}{|l|}{ Group } \\
\hline Intervention & $10(66.7 \%)$ & 47 (48.5\%) & \\
\hline Control & $5(33.3 \%)$ & $50(51.5 \%)$ & 1.72 \\
\hline \multicolumn{4}{|l|}{ Amount of hours online each day } \\
\hline Less than 1 hour & $0(0 \%)$ & $6(6.2 \%)$ & \\
\hline $1-3$ hours & $5(33.3 \%)$ & 58 (59.8\%) & \\
\hline $3+$ & $10(66.7 \%)$ & $33(34.0 \%)$ & $6.15^{*}$ \\
\hline
\end{tabular}

*Significant at $\mathrm{p}<0.05$. 
Table 2. Sociodemographic and diffusion information about referrals, Los Angeles, CA 2012.

\begin{tabular}{|c|c|c|c|}
\hline & $\begin{array}{l}\text { Referred by Control } \\
\text { Group Participant } \\
(\mathrm{n}=13)\end{array}$ & $\begin{array}{l}\text { Referred by Intervention } \\
\text { Group Participant } \\
(\mathrm{n}=54)\end{array}$ & $\begin{array}{c}\text { Total } \\
(\mathrm{N}=67)\end{array}$ \\
\hline Completed survey & $5(38.5 \%)$ & $39(72.2 \%)$ & $44(65.7 \%)$ \\
\hline Age (mean (SE)) & $24.2(1.71)$ & 30.99 (1.11) & $30.11(1.05)$ \\
\hline \multicolumn{4}{|l|}{ Race } \\
\hline African American & $1(20.0 \%)$ & $3(7.7 \%)$ & $4(9.1 \%)$ \\
\hline Latino & $3(60.0 \%)$ & 17 (43.6\%) & $20(45.5 \%)$ \\
\hline White & $1(20.0 \%)$ & $13(33.3 \%)$ & $14(31.8 \%)$ \\
\hline Asian & $0(0 \%)$ & $6(15.4 \%)$ & $6(13.6 \%)$ \\
\hline \multicolumn{4}{|l|}{ Education } \\
\hline High school or less & $4(80.0 \%)$ & $7(18.4 \%)$ & $11(25.0 \%)$ \\
\hline GED or Associate's degree & $0(0 \%)$ & $8(21.0 \%)$ & $8(18.2 \%)$ \\
\hline Bachelor's degree & $0(0 \%)$ & $16(42.1 \%)$ & $16(36.4 \%)$ \\
\hline Graduate school & $1(20.0 \%)$ & $7(18.4 \%)$ & $8(18.2 \%)$ \\
\hline \multicolumn{4}{|l|}{ Amount of hours online each day } \\
\hline Less than 1 hour & $0(0 \%)$ & $2(5.1 \%)$ & $2(4.5 \%)$ \\
\hline 1 - 3 hours & $3(60.0 \%)$ & 15 (38.5\%) & $18(40.9 \%)$ \\
\hline $3+$ & $2(40.0 \%)$ & $22(56.4 \%)$ & 24 (54.5\%) \\
\hline \multicolumn{4}{|l|}{ Sex } \\
\hline Male & $5(100 \%)$ & 31 (79.5\%) & $36(81.8 \%)$ \\
\hline Female & $0(0 \%)$ & $8(20.5 \%)$ & $8(18.2 \%)$ \\
\hline \multicolumn{4}{|l|}{ Sexual orientation } \\
\hline Gay & $5(100 \%)$ & 25 (64.1\%) & $30(68.2 \%)$ \\
\hline Bisexual & $0(0 \%)$ & $1(2.6 \%)$ & $1(2.3 \%)$ \\
\hline Heterosexual & $0(0 \%)$ & $11(28.2 \%)$ & $11(25 \%)$ \\
\hline Questioning/don't know & $0(0 \%)$ & $2(5.1 \%)$ & $2(4.5 \%)$ \\
\hline \multicolumn{4}{|l|}{ Have any of your friends talked to you about the HOPE UCLA Study? } \\
\hline No & $1(20.0 \%)$ & $16(41.0 \%)$ & $17(38.6 \%)$ \\
\hline Yes & $4(80.0 \%)$ & $23(59.0 \%)$ & $27(61.4 \%)$ \\
\hline \multicolumn{4}{|l|}{ Did your friend talk to you health behaviors? } \\
\hline No & $1(20.0 \%)$ & $19(48.7 \%)$ & $20(45.5 \%)$ \\
\hline Yes & $4(80.0 \%)$ & $20(51.3 \%)$ & $24(54.5 \%)$ \\
\hline \multicolumn{4}{|c|}{ After talking to your friend, likelihood of changing which of the following health behaviors? } \\
\hline Exercise (n, Mean) & 4, 3.25 & $23,3.43$ & 3.41 \\
\hline Eat healthier & 4, 3.25 & $23,3.47$ & 3.44 \\
\hline Have safer sex (such as using condoms) & 4,4 & $23,3.7$ & 3.74 \\
\hline Get an HIV test & $3,3.0$ & 23, 3.4 & 3.37 \\
\hline Not smoke/reduce or quit smoking & 4, 3.75 & 23, 3.4 & 3.44 \\
\hline
\end{tabular}

networks to join an online community and then deliver an intervention to these seeds. This approach might allow intervention information to rapidly and simultaneously diffuse throughout multiple community members' social networks.

Online social networks were important not only as a diffusion platform but also to improve data quality by allowing us to view referrals' Facebook networks and verify they were unique people who were connected to the 
seeds. Multiple respondents (i.e., completing duplicate surveys to receive compensation) adversely affect data quality in online research. If referrals had completed surveys without first providing their social networking profile, it would be easy for them to have completed duplicate surveys. However, being able to link to their social networking profile provided an additional validation that the referral was unique and was linked on Facebook to the seed. This is one example of how online social networks will become increasingly useful tools for improving data quality in online studies [14].

This feasibility study has limitations, primarily related to sample size and lack of established methods for measuring diffusion from a social networking community. First, our data included a small number of referrals. Due to IRB recommendations that we wait for referrals to contact us, we were unable to 1) gain a larger sample of referrals by reaching out directly to participants networks, or 2) determine the number of people contacted by HOPE participants who did not email us for to request study information. Due to these methodological constraints, we received only a modest number of survey responses (13\% referral rate) out of the total number of possible referrers. However, we believe that $13 \%$ is actually an encouraging number as 1 ) seeds were participants from a study that was conducted 1 year prior, and 2) these participants were picked because they were previous participants, but had expressed no interest in wanting to contact other people to complete a survey. Next, we made no attempt to reflect intraclass association among referrals from the same seed. These issues made it difficult to conduct a formal statistical analysis on the success of the intervention in spreading outside of the intervened community and throughout participants' social networks. However, at an aggregate level, most referrals reported that their seed at least talked to them about the health intervention and the importance of health behavior change. This provides initial support that social networking-based community health interventions might diffuse outside of the initial online community and through participants' social networks. This study presents one approach for measuring diffusion, i.e., contacting participants from the original intervention and asking them to refer their friends. Future research may build upon this study by using a larger initial community in order to gather sufficient data to measure diffusion, as well as by using more objective measures of assessing diffusion.

\section{Conclusion}

The present methods demonstrate the feasibility of using social networking for diffusion of online health interventions and provide a call for additional research on this new topic.

\section{Funding}

The authors wish to thank the National Institute of Mental Health (K01 MH 090844) for funding this research. Additional funding was provided by the UCLA Center for HIV Identification, Prevention, and Treatment Services (CHIPTS) through NIMH grant P30 MH 58017.

\section{Conflict of Interests}

No conflicts of interest to declare.

\section{References}

[1] Kelly, J.A., Murphy, D.A. and Sikkema, K.J. (1997) Randomised, Controlled, Community-Level HIV-Prevention Intervention for Sexual-Risk Behaviour among Homosexual Men in US Cities. Lancet, 350, 1500-1505. http://dx.doi.org/10.1016/S0140-6736(97)07439-4

[2] Maiorana, A., Kegeles, S., Fernandez, P., Salazar, X., Caceres, C., Sandoval, C. and Coates, T. (2007) Implementation and Evaluation of an HIV/STD Intervention in Peru. Evaluation and Program Planning, 30, 82-93. http://dx.doi.org/10.1016/j.evalprogplan.2006.10.004

[3] Young, S.D., Konda, K., Galea, J., Sung-Jae, L., Salazar, X., Sanchez, J. and Coates, C. (2011) Effects of an HIV/STI Community Peer Leader Intervention on Stigma in Peru. AIDS and Behavior, 15, 930-937. http://dx.doi.org/10.1007/s10461-010-9826-5

[4] Rogers, E.M. (1995) Diffusion of Innovations. 4th Edition, Free Press, New York.

[5] Amirkhanian, Y.A., Kelly, J.A., Kabakchieva, E., Kirsanova, A.V., Vassileva, S. and Mocsonaki, L. (2005) A Randomized Social Network HIV Prevention Trial with Young Men Who Have Sex with Men in Russia and Bulgaria. AIDS, 19, 1897-1905. http://dx.doi.org/10.1097/01.aids.0000189867.74806.fb 
[6] St. Lawrence, J.S., Brasfield, T.L., Diaz, Y.E., Jefferson, K.W., Reynolds, M.T. and Leonard, M.O. (1994) Three-Year Follow-Up of an HIV Risk-Reduction Intervention That Used Popular Peers. American Journal of Public Health, 84, 2027-2028. http://dx.doi.org/10.2105/AJPH.84.12.2027

[7] Bull, S.S., Levine, D.K., Black, S.R., Schmiege, S.J. and Santelli, J. (2012) A Social Media Delivered Sexual Health Intervention: A Cluster Randomized Controlled Trial. American Journal of Preventive Medicine, 43, 467-474. http://dx.doi.org/10.1016/j.amepre.2012.07.022

[8] Jaganath, D., Gill, H.K., Cohen, A.C. and Young, S.D. (2011) Harnessing Online Peer Education (HOPE): Integrating C-POL and Social Media to Train Peer Leaders in HIV Prevention. AIDS Care, 24, 593-600. http://dx.doi.org/10.1080/09540121.2011.630355

[9] Klatt, C., Berg, C.J., Thomas, J.L., Ehlinger, E., Ahluwalia, J.S. and An, L.C. (2008) The Role of Peer E-Mail Support as Part of a College Smoking-Cessation Website. American Journal of Preventive Medicine, 35, S471-S478.

[10] Valente, T.W. (2012) Network Interventions. Science, 337, 49-53. http://dx.doi.org/10.1126/science.1217330

[11] Valente, T.W. and Fosados, R. (2006) Diffusion of Innovations and Network Segmentation: The Part Played by People in Promoting Health. Sexually Transmitted Diseases, 33, S23-S31. http://dx.doi.org/10.1097/01.olq.0000221018.32533.6d

[12] Young, S.D., Cumberland, W., Sung-Jae, L., Jaganath, D., Szekeres, G. and Coates, T. (In Press) Social Networking Technologies as Emerging Tools for HIV Prevention: A Randomized Controlled Trial. Annals of Internal Medicine.

[13] Young, S.D. and Jaganath, D. (In Press) Online Social Networking for HIV Education and Prevention: A Mixed Methods Analysis. Sexually Transmitted Diseases. http://dx.doi.org/10.1097/OLQ.0b013e318278bd12

[14] Young, S.D. (2012) Recommended Guidelines on Using Social Networking Technologies for HIV Prevention Research. Aids and Behavior, 16, 1743-1745. http://dx.doi.org/10.1007/s10461-012-0251-9 